Columbia Law School

Scholarship Archive

2013

\title{
Desistance and Legitimacy: The Impact of Offender Notification Meetings on Recidivism Among High Risk Offenders
}

\author{
Andrew V. Papachristos \\ andrew.papachristos@yale.edu \\ Danielle M. Wallace \\ Arizona State University (ASU), danielle.wallace@asu.edu \\ Tracey L. Meares \\ t-meares@uchicago.edu \\ Jeffrey Fagan \\ Columbia Law School, jfagan@law.columbia.edu
}

Follow this and additional works at: https://scholarship.law.columbia.edu/faculty_scholarship

Part of the Criminal Law Commons, Criminal Procedure Commons, and the Law and Society Commons

\section{Recommended Citation}

Andrew V. Papachristos, Danielle M. Wallace, Tracey L. Meares \& Jeffrey Fagan, Desistance and Legitimacy: The Impact of Offender Notification Meetings on Recidivism Among High Risk Offenders, Yale LaW \& Economics Research Paper No. 469; Columbia Public law Research Paper No. 13-343 (2013). Available at: https://scholarship.law.columbia.edu/faculty_scholarship/1799

This Working Paper is brought to you for free and open access by the Faculty Publications at Scholarship Archive. It has been accepted for inclusion in Faculty Scholarship by an authorized administrator of Scholarship Archive. For more information, please contact scholarshiparchive@law.columbia.edu. 


\section{Columbia Law School}

Public Law \& Legal Theory Working Paper Group

Paper Number 13-343

Desistance and Legitimacy: The Impact of Offender Notification Meetings on Recidivism among High Risk Offenders

Andrew V. Papachristos

Yale University, Department of Sociology

Danielle Wallace

Arizona State University,

School of Criminology and Criminal Justice

Tracey Meares

Yale University, Law School

Jeffrey Fagan

Columbia University, Law School

March 27, 2013 


\title{
Desistance and Legitimacy: The Impact of Offender Notification Meetings on Recidivism among High Risk Offenders ${ }^{1}$
}

\author{
Andrew V. Papachristos ${ }^{*} \sim$ Yale University, Department of Sociology \\ Danielle Wallace Arizona State University, School of Criminology and Criminal Justice \\ Tracey Meares Yale University, Law School \\ Jeffrey Fagan Columbia University, Law School
}

\begin{abstract}
Objective: Legitimacy-based approaches to crime prevention operate under the assumption that individuals - including violent offenders - are more likely to comply with the law when they believe that the law and its agents are legitimate and act in ways that seem inherently "fair" and "just." While mounting evidence finds an association between such legitimacy-based programs and reductions in aggregate levels of crime and violence, no study has investigated whether such programs influence individual offending. This study evaluates the effectiveness of one such program — Project Safe Neighborhoods' (PSN) Offender Notification Meetings—at reducing individual recidivism among a population of returning prisoners in Chicago.
\end{abstract}

Methods: This study uses a quasi-experimental design and two types of survival analyses (Cox hazard models and competing risk models) to evaluate the effects of PSN on the subsequent recidivism of program participants relative to the control group.

Results: Cox hazard models and competing risk models suggest that involvement in PSN significantly reduces the risk of subsequent incarceration. In fact, participation in PSN Offender Notification Forums is associated with a significant lengthening of the time that offenders remain on the street and out of prison.

Conclusion: This study provides some of the first individual-level evidence of the efficacy of such programs on patterns of individual offending. Results suggest that interventions such as these do indeed reduce rates of recidivism in the treatment group.

"Corresponding Author. Please direct all inquires to andrew.papachristos@yale.edu 


\section{INTRODUCTION}

While deterrence-based crime reduction strategies remain the mainstay of criminal justice policy, a series of innovative and promising programs has emerged based on the concepts of procedural justice and legitimacy. The underlying premise of such programs is that individualsincluding violent offenders (Papachristos, Meares and Fagan 2012) — are more likely to comply with the law when they believe that the law and its agents are legitimate and act in ways that seem inherently "fair" and "just" (Tyler 1997). Programs that enhance the legitimacy of the law and police should foster higher levels of compliance. Examples of programs demonstrating characteristics of procedural justice potentially leading to legitimacy include Boston's Operation Ceasefire (Braga, Piehl and Hureau 2009), Chicago's Project Safe Neighborhoods initiative (Papachristos, Meares and Fagan 2007a), and North Carolina's Drug Market Initiative (Kennedy and Wond 2009). Each of these initiatives relied upon two strategies: one that informed participants of the consequences of illegal conduct consistent with theories of deterrence and two, promoting legitimacy by recasting law enforcement interactions with the offending population. Instead of employing hierarchical and aggressive tactics that typify deterrence-based police-offender interactions, these programs conveyed the consequential messages in a nonthreatening manner along side community stakeholders. Additionally, the meetings with offenders where held in places of civic importance, such as libraries, community centers, and churches. Thus, despite the centrality of informing offenders of the consequences of bad choices, the interventions themselves were specifically crafted to be transparent and fair, as well as promote a sense of police legitimacy.

Research supports the efficacy of such a legitimacy-based approach to crime prevention. In addition to the mounting evidence that legitimacy is related to aggregate crime rates (Corsaro, 
Brunson and McGarrell 2009; Kirk and Matsuda 2011; Kirk and Papachristos 2011; McGarrell et al. 2010) and more general compliance with the law (Tyler 1997), there is an agreement in the experimental policing literature that legitimacy based policing strategies are associated with reductions in aggregate levels of crime (see Braga and Weisburd 2012). However, to the best of our knowledge, no study has yet explored the extent to which legitimacy-based programs impact the level of individual offending. That is, while mounting evidence exists of the community-level impact of legitimacy based programs, we still do not know if the individual participants in such programs adjust their behavior accordingly.

To address this shortcoming, using a quasi-experimental design, we examine how an intervention designed to enhance legal legitimacy influences recidivism among a group of recently released felons who participated in Chicago's Project Safe Neighborhoods (PSN) program. We combine the design of the PSN field experiment itself with individual data on recidivism and socio-demographic characteristics to assess the programmatic effects of Offender Notification Forums: an intervention that brought together offenders, police, community stakeholders, and service providers in an hour long meeting regarding levels of violence in the community, the implications of the offenders' continued participation in violence, and the provision of services tailored specifically to the needs of re-entering offenders. Cox hazard models and competing risk models suggest that involvement in the PSN program significantly reduces the risk of subsequent incarceration: indeed, attendance at PSN Forums is associated with a significant lengthening of the time that offenders remain on the street and out of prison.

The paper proceeds as follows. First, we describe the premise behind the growing interest in legitimacy based crime prevention strategies. Next, we describe the design and implementation of the Offender Notification Forums. Finally, we present the results of our 
survival models as well as the implication for policy and research.

\section{Behind OfFender Notification Forums: Focused Deterrence and Procedural JUSTICE}

This study examines the efficacy of a specific type of legitimacy-based program aimed at reducing recidivism-Offender Notification Forums (hereafter, "Forums"). Although the actual architecture of these Forums varies by municipality ${ }^{2}$, the underlying structure and idea are consistent. At their core, Forums are brief meetings (typically no more than an hour long) bringing together law enforcement, community stakeholders, service providers, and active offenders. The message of the meeting is straight-forward: "Your community needs the violence to stop and we'd like to help you and those in your group/gang/crew stop that violence." Participants are warned that they have been "put on notice": the law enforcement community is aware of their involvement and, should they continue shooting, law enforcement will be working together to focus on the violence in this area. Any subsequent violent behavior on their part will result in all of the stakeholders pulling every available "lever" (enforcement and civil action) against the offender and his group (Corsaro et al. 2012; Kennedy 1996; McGarrell et al. 2010).

The primary theoretical principle undergirding the Forums is procedural justice-based legitimacy. Broadly defined, legitimacy is "the widespread belief among members of the public that the police, the courts, and the legal systems are authorities entitled to make decisions and who should be deferred to concerning matters of criminal justice” (Tyler 2010, p. 127; also, Tyler 1997). The legitimacy of the police and courts is often determined through the perceived fairness of the manner in which this authority is exercised-a process called procedural justice (Tyler 1997). To summarize this growing area of theorizing and research, if interactions with legal authorities and the procedures for criminal justice are thought to be fair and just then 
individuals are more likely to (a) view those agents of the law as legitimate and (b) comply with the law, even when behavior is not directly monitored (Tyler and Fagan 2008; Tyler and Huo 2002). Programmatic efforts focusing on procedural justice aim to increase the legitimacy of legal actors and authorities, and in so doing, increase levels of compliance.

The Offender Notification Forums analyzed here rely on the notion that an offender's perceptions of the law and by extension his compliance with the law can be increased through positive and legitimate interactions with police. Namely, interactions and interventions that are conducted in a way that is fair and just should increase overall beliefs in the legitimacy of the law and subsequent compliance. Evidence for such an approach can be found in Paternoster et al's (1997) study of a domestic violence program in which offenders were more likely to say that their detention or sentence was "fair" when they were treated with respect by police and prosecutors. More recently, Papachristos et al's (2012) study on 141 active gun offenders in Chicago finds that respondents' opinions of the law were indistinguishable from those found in the general population estimates such as those by Tyler and Huo (2002) - i.e., criminals, not just non-criminals, express a belief in the moral foundation and legitimacy of the law. Criminals differ from non-criminals, however, when their expressing more negative interactions and opinions with the police (Papachristos, Meares, and Fagan 2012). That is even though criminals believe in the substance of the law, they do not believe that many of the agents of the law are legitimate. Nonetheless, this study finds that perceptions of legitimacy $d o$ influence compliance: offenders with more positive views of the police were less likely to carry a gun or get into a fight (Ibid.).

The Forums aim to strengthen the legitimacy of the police and the criminal justice system and therefore compliance among a very specific population - those offenders actively involved 
in crime and violence. One might think this a Herculean task as the offender population invited to the Forums focus are young minority males, a population more likely to have more interactions with law enforcement agents than other groups, which they often view as negative (Carr, Napolitano and Keating 2007; Hagan, Shedd and Payne 2005). Consider the recent debates surrounding the "stop-and-frisk" practices in New York City. Fagan and colleagues (Fagan et al. 2009) have estimated that the probability of being stopped by police for AfricanAmerican men ages eighteen to nineteen residing in New York City in 2006 was between 78\% and $80 \%$ while the corresponding probabilities for Hispanic males and non-Hispanic white males for the same time period were $35 \%$ and $45 \%$ and $10 \%$ and $13 \%$ respectively. More troubling is the fact stops were more likely to lead to arrest for whites than for blacks. Young minority men not only have increased contact with the police, but also with other actors in the criminal justice system. Nearly 1 in 3 black men between the ages of twenty and twenty-nine is under correctional supervision (jail, prison, probation, or parole) and incarceration is now the modal experience for black men without a high-school diploma as roughly sixty percent will experience incarceration during their lifetime (Western 2006). It is likely that these high levels of contact lead to negative perceptions. Research demonstrates that these young men, like African Americans generally, have a high preponderance of negative opinions of the criminal justice system and especially police (Fagan et al. 2009; Hagan, Shedd and Payne 2005). ${ }^{3}$

The program analyzed here (and those related to it; for a review, see McGarrell et al. 2010) takes as its goal changing the perceptions of legitimacy among a population of young men known to have high levels of mistrust and cynicism towards the criminal justice system and low levels of procedural justice (Fagan and Piquero 2007). More than that, the Forums are attempting to alter the perceptions of active offenders - a population that many criminological theories 
assume to have less regard for the law and its agents than their law-abiding counterparts (for example Reisig, Wolfe and Holtfreter 2011; Sherman 1993; Wolfe 2011) and are differentially effected by sanction threats (Loughran et al. 2012).

To date evaluations of Forums and similar programs have been extremely encouraging. Cities employing Forums as part of focused deterrence strategies include Boston (Braga, Hureau and Papachristos forthcoming; Braga et al. 2001), Chicago (Papachristos, Meares and Fagan 2007a), Cincinnati (Engel, Tillyer and Corsaro forthcoming), and High Point, NC (Corsaro et al. 2012) and in all of those instances, the targeted communities experienced a reduction in aggregate rates of violence (see Braga and Weisburd 2012 for a review). However, only the Chicago study (Papachristos, Meares and Fagan 2007a), which is a strategy designed explicitly to leverage the potential benefits of legitimacy-based compliance, actually measured and compared the effect of attending a Forum vis-à-vis other forms of intervention. Papachristos and colleagues (2007) find that the percentage of the offending population in a community that attends such a Forum exerts the greatest crime reduction effect in their analysis, greater than the number of federal prosecutions, sentence length, and heightened gun policing.

While mounting evidence suggests that such legitimacy based efforts are associated with declines in aggregate levels of crime and violence, no study to the best of our knowledge has examined the impacts of Forum attendance on individual outcomes. The present study addresses this shortcoming by analyzing the effect of Forum participation on individual recidivism among individuals recently released from prison who participated in the Chicago Project Safe Neighborhoods Program.

\section{Project Safe Neighborhoods in Chicago}


Since 2002, a Department of Justice funded program called Project Safe Neighborhoods (PSN) has been implemented in Chicago with the specific charge of reducing the city's high levels of homicide and gun violence. Under the direction of the U.S. Attorney for the Northern District of Illinois, Patrick Fitzgerald, PSN brought together local, state, and federal law enforcement agencies with community based organizations and researchers with the specific purpose of devising context-specific gun violence reduction strategies. In practice, PSN entailed not a single program, but rather a series of related initiatives directed towards specified communities. As summarized by Papachristos et al. (2007) these efforts included: (1) increased federal prosecutorial attention for all gun-related crimes; (2) the creation of a local and federal review system of all gun-related cases brought before the court; (3) the creation of a multiagency gun enforcement team; (4) community and media outreach campaigns; (5) school based educational programs; and (5) the Offender Notification Forum.

PSN efforts were focused in two ways: geographically and individually. Geographically, all of these efforts were directed towards specified areas of the city-essentially two police districts on Chicago's west-side that include the West Garfield Park, North Lawndale, and the Austin community areas. While PSN areas were selected chiefly because of political pressure over rising rates of violence, subsequent problem analyses revealed that these areas (at least in part) would have risen as likely candidates for PSN since at the time of the intervention they had some of the highest and most stable crime rates in the city (Papachristos et al. 2007). Indeed, homicide rates in the PSN districts at the time of the intervention in 2002 were approximately 75.5 per 100,000, a staggering 350 percent higher rate than the overall city average of 22.3 per 100,000 (which itself was incredibly high). This non-random selection notwithstanding, propensity score modeling and the timing of the intervention permitted the creation of a quasi- 
experimental design that matched neighborhoods within the intervention areas with other highcrime neighborhoods in other parts of the city.

Within the treatment areas, PSN programs with the exception of the school-based and community outreach efforts were directed specifically towards "active" offenders, meaning those individuals who were known by authorities to likely be involved in criminal and gang activities. Prior research suggests that the majority of violence is highly concentrated among small segments of the male population (Braga 2003; Loeber and Farrington 2011; Papachristos, Braga and Hureau 2012; Wolfgang 1958). More importantly, such findings encouraged PSN, demonstrating that focused deterrence efforts directed at this population might very well be the most efficient way to reduce overall levels of homicide and gun violence.

Papachristos and colleagues' (2007) evaluation found strong and consistent support for a crime reduction effect of PSN on neighborhood-level rates of homicide and violence. Using individual level growth curve models and propensity scores to adjust for nonrandom group assignment of neighborhoods, Papachristos et al. (2007) found a that PSN efforts were associated with a roughly 37 percent reduction of quarterly homicide rates in the treatment areas as compared to the control areas. Specific treatment effects were measured for all of the PSN initiatives, but the results consistently show that the largest effects were associated with the Offender Notification Forums. ${ }^{4}$ The impact of the Forums were measured as "saturation," the percentage of the eligible offending population within the community that had attended a Forum with a one percentage increase in the saturation associated with an approximately 13 percentage point decrease in the neighborhood-level log homicide rate (Papachristos et al. 2007, pg. 256). PSN-style Offender Forums, and other similar legitimacy based meetings, increased in popularity and have shown significant associations with reduced levels of crime in other 
municipalities. Nearly all of this research, however, analyzes changes in aggregate (usually citywide) crime rates. The main objective of this study is to pick up where this prior research leaves off by examining the influence of Forums on individual patterns of co-offending. If the legitimacy based philosophy of Forums is driving the observed crime reductions, then it might be operating at the level of the individual—namely, offenders who attend these meetings might be changing their behavior. Before testing this hypothesis, we first describe in a bit more detail the design, architecture, and implementation of the Forums.

\section{FORUM DESIGN, ARCHITECTURE, AND IMPLEMENTATION}

The Offender Notification Forums are one-hour long meetings in which members of the PSN team sit down with a group of approximately 25 individuals recently released from prison. Individuals are randomly selected to attend the Forums based on three criteria: (1) residence in the target communities, (2) at least one prior gun-related or violent offense in their criminal records, and (3) recently release from prison (the preceding 3 to 6 months). Individuals selected to attend the meeting received a standard invitation letter in the mail, as well as a follow-up letter and phone call from their parole/probation officer. Attendance was not mandatory, and attendance rates were on average above 65 percent. Often times, individuals missing a meeting would attempt to quickly reschedule for the next meeting. The first Forum was held in January 2003 and continues to the present day.

As mentioned above, the overarching goal of the Forums is to alter the generally negative opinions offenders might have of law enforcement while simultaneously delivering the deterrence-based message. The guiding principle of the PSN team was to accomplish this objective by designing an intervention that changed the interactions between law enforcement 
and offenders. As such, the PSN team drafted and monitored the Forums to ensure that they proceeded with these guiding principles in mind during all aspects of program. ${ }^{5}$

First and foremost, the setting of the forum is aimed at creating an environment that conveys equity among all parties and participants. Rather than hold the forums at a law enforcement venue, the forums are held at places of "civic importance," such as parks, community colleges, or churches. Holding the forums in a neutral setting makes the offenders more comfortable as well as changes the power dynamics between law enforcement and offenders because of the neutrality of the location. The signal is subtle but essential: you are not in custody; this is a safe place in your community. The physical arrangement of the meeting conveys a similar message because the Forum is conducted in a round. Speakers are not segregated to the front of the room with the participants facing them classroom or lecture-style. Instead, tables are chairs are arranged in a circle; speakers and participates face each other and speakers generally do not stand when they give their message. Thus, the Forum atmosphere that is not didactic or authoritarian, but rather "we're all at the same table" - a message that resonates in with the content of Forum.

Coupled with an egalitarian atmosphere is a firm yet fair deterrence principle: treat people like 'normal' adult citizens, give them a choice, and respond as promised when they reoffend. This message is delivered in three parts: (1) law enforcement efforts, (2) the ex-offender experience, and (3) social service provision. The Forums begin with the law enforcement message, which is a simple one: if you pick up a gun or are involved in a gun-related crime after this meeting, the people in this room will "pull every [deterrent] lever" at their disposal to enforce the law (the Kennedy 1997). Here, representatives from the multiple law enforcement agencies, such as the Chicago Police Department, ATF, Cook County State's Attorney, and the 
United States Attorney's Office, speak regarding the various avenues they can take to arrest and prosecute returning gun offenders. Special attention is paid to the consequences of federal prosecutions relative to state-level penalties. Recent PSN related cases- those that occurred with PSN districts—are described in detail, and while forum attendees are often familiar with the defendant, they are often surprised to hear the sentencing outcomes.

While the main thrust of the law enforcement message is deterrence focused, it nonetheless is coupled with the sense of choice and respect. That is, law enforcement speakers stress their concern for the overall levels of violence in the community, and suggest that they too hope the offenders "change their ways" since they are most likely to be a victim. Illustrative of this approach, one local prosecutor's remarks at the forum concluded as follows:

We don't want to see you again, because, if we do, it'll be either on a piece of paper as someone who picked up a gun, or as a victim. I see too many people hurt and, believe it or not, I don't want to see you on a slab. Go out and be producers. Don't destroy the community any more. ${ }^{6}$

Thus, after the powerful delivery of the deterrence-centered messages, law enforcement speakers reiterate the central themes of fairness, encouraging the attendees to engage rather than offend.

The ex-offender segment of the Forum is usually run by a single individual who has successfully stayed away from offending for several years and, most often, is actively engaged in community activities. This speaker's message stresses the seriousness of the current levels of violence in the community, the problems of intra-racial violence, the truth about gang life (including its meager financial rewards), the troubles offenders face when looking for work, and the seriousness of the PSN enforcement efforts. This section tends to be the most motivational and emotional of the three as the speaker makes particular empathetic connections to the attendees. 
Consistent with the legitimacy-based message, the ex-offender messages underscore the theme of change and how the PSN team is giving them an opportunity—a "heads up"—on what will happen to them should they pick up a gun. Change is difficult but possible as one speaker put it:

There's a saying, 'Change is a choice, but accountability is a guarantee.' They [pointing to the law enforcement members] are sitting here and telling you they [are] coming after you [if you leave here and pick up a gun]. Gonna hold you accountable. Ain't no one ever tell me that. Now, I don't mean no disrespect, but if you ain't listening, you got to be a fool...I changed. It was a choice, a real hard one. But I did it... Once you change your life around, you'll have a whole new respect for others and yourself.

The final segment of the Forums entails a series of presentations and discussions by representatives from community, educational, health, and employment service providers. The speakers from the local social service providers enforce the message that re-offending is a choice, though, in tandem with that point, they offer options and support. These speakers will often talk about the programs they work for and services that they offer. For example, one local service provider often discusses how their agency helps ex-offenders obtain licenses and other documents they need to apply for jobs. In essence, their message is "we're here for you; here are some local things you might need to succeed." Both the ex-offender and the community social service provider messages provide something different for the offenders. Rather than a deterrence message that law enforcement often gives, the ex-offender and the community social service providers convey that it is possible to stay crime-free, and there is local support to help the ex-offender remain crime free.

The meetings typically last the allotted one hour. Based on the observations of the authors, roughly half of the attendees at any given meeting quickly leave the meeting without chatting to anyone else. The other half of the attendees, however, often stayed behind talking 
with service providers, signing up for services, and simply talking with members of the PSN team. Indeed, it was quite common for such conversations to last an additional hour with informal conversations spilling out into the corridors and street. And, often, those informal conversations included candid discussions between attendees and local, state, and federal law enforcement.

\section{DATA AND Methods}

\section{Data sources}

In order to test the effect the PSN program has on recidivism, we employ individual level recidivism data provided by the Illinois Department of Corrections (IDOC) ${ }^{7}$. This data contains the population of individuals released from prison between 2001 and 2006 in Cook County, Illinois, who have had a felony weapons violation at some point in time in their criminal history. Essentially, this is the population of offenders who would be eligible to receive the PSN treatment. Data contains detailed information on each re-entering individual, including any reincarcerations during the study years, individual sociodemographic characteristics, date of release, offense description, gang membership, zip code of release, and finally, participation in the PSN program.

To test the effects of the PSN Forums, we examine the recidivism patterns for the first cohort of individuals who were eligible for PSN. Keeping with the overall quasi-experimental design described by Papachristos et al. (2007), we restrict the data to the districts that served as the site of the PSN intervention. This enables us to compare those that received the PSN treatment or lived in a PSN neighborhood to other returning offenders who live in a comparable 
neighborhood in regard to sociodemographic characteristics and crime rates rather than to the whole of Chicago.

\section{Recidivism and Time to Re-arrest Measures}

Recidivism is defined as any re-incarceration during the study years. Because we are analyzing a long time frame, there is the possibility of multiple rearrests for one individual. Therefore, we explore only the first re-arrest event contained within the data. Additionally, for our sample, individuals are right censored when they do not recidivate during the study years. In the event that an individual is rearrested, we calculate, in months, the time between their release into the community from the prior offense to the date of their re-arrest; we refer to this measure as time on the street.

Re-arrest events were characterized in three ways. First, we delineated recidivism as a binomial variable of 0 - was not rearrested, and 1 - was re-arrested. Second, we characterized recidivism from a competing risks stand point where individuals were censored, arrested for a new offense, or arrested for a technical violation. Lastly, we also characterized by Uniform Crime Report offense types, namely, murder, violent crimes, violent property crimes, drug sales, drug possession, weapons violations, other property crime, drug conspiracies, and other UCR crimes. In this case, recidivism is coded as arrested for the UCR crime of interest versus arrest for some other crime.

\section{Independent Variables and Controls}

The main independent variable of interest is designation showing whether or not a returning prisoner was part of the PSN program and attended the offender forum. Of the 4,420 
individuals in the data, 238 (approximately 5 percent) were part of the PSN program. We designate this by a dummy variable representing that the individual was part of the PSN Experimental Group. Other controls included dummy variables for Black ( $1=$ yes), whether the returning prisoner had a high school diploma or equivalent $(1=$ yes $)$, children $(1=$ yes $)$, were married $(1=$ yes $)$, were cohabitating with a significant other $(1=y e s)$, a gang member $(1=$ yes $)$, or living in the experimental PSN neighborhood ( 1 = yes). Additionally, we controlled for age in years, and the number of prior incarcerations, where 0 meant no previous incarcerations, 1 equaled one prior incarceration, 2 equaled two prior incarcerations, and 3 equaled three or more prior incarcerations. Table 1 shows the summary statistics for all variables used in our models.

$$
\text { [--- Table } 1 \text { about here --- }]
$$

\section{Modeling Strategy}

In this paper, we employ two types of survival analysis: Cox proportional hazard models, and competing risk hazard models. First, we estimate the time to re-arrest using the Cox proportional hazard models, which do not assume any specific shape for the underlying survival function (i.e., who is not rearrested) (Lee and Wang 2003; Wu and Tuma 1991; Yamaguchi 1991). Here, the hazard rate is affected by the independent variables, not the survival function (Allison 1984; Allison 1995). The model is written as:

$$
h(t)=h_{0}(t) \exp \left(\beta_{1} x_{1}+\cdots+\beta_{k} x_{k}\right)
$$

The hazard function given the values of the covariates $x_{k}$ for cases one through $k$ is denoted by $h(t, \ldots)$ for survival time $t$. The baseline hazard is represented by $h_{0}(t)$. Failure is measured as any re-arrest within the time period of our study. Finally, individuals who were not 
rearrested during the study period are right censored. These models will allow us to understand the general effects that participation in the PSN program has on time to re-arrest.

While the PSN program aimed to reduce recidivism in general, it more specifically sought to reduce the occurrence of new violence and gun offenses. Standardized Cox models will not allow for the differentiation between various classifications of re-arrest events. Therefore, we employ competing risk models to determine the risk of re-arrest for one type of offense versus another. Competing risk models are most commonly specified in medical and public health research where the researcher is interested in time to failure (for example, death) from the disease of interest, controlling for the possibility that failure can occur through other means. In this study, we are interested in how participation in PSN Forums in time to re-arrest for new sentences, controlling for the fact that re-arrest can also occur via technical violations (and vice versa), for example. As such, are concerned about time to re-arrest, or the failure function, rather than the time to survival. We employ competing risk hazard models to model the following competing risks: (1) new sentences versus technical violations, (2) murder versus non-murder rearrests, (3) violent crimes versus non-violent crime rearrests, (4) violent property crimes versus non-violent property crime rearrests, (5) drug sales versus non-drug sale rearrests, (6) drug possession versus non-drug possession rearrests, (7) weapons violations versus non-weapons violations re-arrest, (8) other property crime versus non-other property crime rearrests, (9) drug conspiracies versus non-drug conspiracies re-arrest, and finally, (10) other UCR crimes versus non-other UCR crime re-arrest. As before, individuals who were not rearrested during the study period are right censored. We consider a competing risk an event that has occurred and prevents the occurrence of the specified event of interest (Fine and Gray 1999). As with most recidivism studies, returning prisoners can recidivate due to a new offense or a technical violation; we want 
to consider both of these possibilities without lumping them into one all-encompassing recidivism outcome. Thus, we specify a competing risk model where the primary failure is recidivism due to the new offense and the competing risk being that of technical violations.

\section{RESULTS}

\section{Overall Recidivism: Within and Between Neighborhoods}

Table 2 displays the coefficients and hazard ratios for the Cox hazard models estimating the time to failure for any incidence of recidivism. These models will give us a general perspective on how the PSN treatment and control groups fair in regards to recidivism, holding the neighborhoods that received treatment constant.

$$
\text { [--- Table } 2 \text { about here --- }
$$

We begin Model 1, the within neighborhood model, which compares individuals within the PSN experimental neighborhood who attended a Forum to those who did not attend a Forum but also live in the neighborhood. Model 1 demonstrates that returning prisoners who are Black, a current gang member or have one or more prior incarcerations have a higher hazard of overall recidivism. Returning prisoners who are older have an increased hazard of recidivating, though this effect is marginally significant $(\mathrm{p}<0.10)$. Conversely, returning prisoners with a high school or equivalent degree and children have a lower likelihood of recidivating. Additionally, our treatment variable is highly significant and negative. Returning prisoners who attended a Forum have a hazard of only 43 percent that of individuals within the same neighborhood who did not attend a Forum. At first glance, receiving PSN treatment lengthens a returning prisoner's time on the street. 
The between neighborhood model (Model 2) compares individuals returning to either the PSN treatment neighborhoods or the control neighborhoods who attended a forum to those who did not attend. In Model 2, we see the statistical significance of many of the same controls: Blacks, current gang members and older individuals have a higher hazard of recidivism. On the other hand, returning prisoners with a high school diploma or GED, are married, or those with children have a lower hazard of recidivating. Like before, the treatment variable is significant: returning prisoners who received the PSN treatment have a hazard of recidivating that is 42.7 percent of returning prisoners who did not receive treatment. The control variable for the PSN experimental neighborhood is non-significant, suggesting that the experimental and control neighborhood are no different in regards to overall recidivism. These general results indicate strongly that the PSN program significantly reduces the likelihood of recidivism and keeps those that do receive treatment on the street longer than returning prisoners who do not. For instance, when looking at the within-neighborhood model, individuals in the PSN program face a hazard of recidivating that is 56.9 percent less than those individuals who are not in the PSN program.

Figure 1 displays the hazard curves for the two treatment and control groups, holding all controls constant. Here, we see that when examining either the within-neighborhood or betweenneighborhood findings, that upon exit, both the treatment and control groups have similar hazards for re-arrest. However, after a year (12 months), the hazard curves are strongly differentiated with the treatment group (the top line) having higher survival rates (i.e., no recidivism) over time. At 60 months, nearly $40 \%$ of the PSN treatment group has not recidivated while less than $10 \%$ of the control group has.

[--- Figure 1 about here ---]

New Sentences versus Technical Violation Recidivism: Competing Risk Hazard Models 
While the above results indicate the PSN treatment has a rather strong effect on lowering the likelihood of recidivism in general and increasing time on the street, they do not offer a detailed view of the types of recidivism happening among the returning prisoners. Table 3 presents a competing risk hazard model where the primary risk is recidivism due to new crimes and the competing risk is recidivism due to a technical violation of parole. Like the previous section, we present our results in two models: within neighborhood competing risks and between-neighborhood competing risks models.

$$
\text { [--- Table } 3 \text { about here ---] }
$$

We begin with the controls in the within neighborhood model, or Model 1, in Table 3. First, individuals with a high school diploma or equivalent and those who are older have a reduced incidence of a new sentence failure compared to younger returning prisoners or those without a high school diploma. Conversely, current gang members and individuals with prior incarcerations have a higher incidence of a new sentence failure. Given the results of the overall recidivism models, these findings are expected.

The coefficient for the treatment variable offers additional insight into the effect of the PSN on recidivism for offenders who attended a Forum. The sub hazard for the PSN group controlling for other variables is about 70 percent of the sub hazard for the control group. In other words, the cohort of returning prisoners receiving PSN treatment have a reduced incidence of a new sentence failure compared to the control group controlling for personal characteristics and the fact that technical violations can also occur. Simply, offenders in the PSN experimental group were less likely of committing a new crime than their counterparts. Given that the coefficients for the PSN Experimental Group are nearly identical for the within- and betweenneighborhood models, we interpret the hazard ratio similarly. Thus, individuals who attended 
PSN Forum face a hazard of committing a new offense that is 30 percent less than those individuals who did not attend.

The between neighborhood model finds similar results. As before, we see that returning prisoners with a high school diploma or equivalent have a reduced risk for a new sentence failures. Similarly, there is a reduced hazard of new sentences for older ages. On the other hand, Blacks (though moderately significant), individuals with multiple prior incarcerations, and who are current gang members have an increased risk of failure due to new sentences versus a technical violation. The PSN treatment variable is again significant; we see that the sub hazard for the PSN group controlling for other variables is about 69.8 percent of the sub hazard for the control group. Thus, individuals in the PSN program face a hazard of committing technical violation that is nearly 70 percent less than those individuals who are not in the PSN program. As before, the PSN experimental neighborhood is non-significant, suggesting that the experimental neighborhood and control neighborhood are no different in regards to the likelihood of failure to new sentences or technical violations. Lastly, the control for the experimental neighborhood is not significant - again showing no significant difference in the hazard of new sentences across the two neighborhoods.

Figure 2 is a comparison of the cumulative incidence new sentences and technical violation failures for our two treatment groups: those individuals in the first cohort and those in the second. The cumulative incidence shown here is the ratio of individuals in that particular group who have failed to those in the total population over time. In both graphs, the cumulative incidence rate is lower for both treatment groups than the control group.

$$
\begin{aligned}
& \text { [--- Figure } 2 \text { about here --- }] \\
& \text { [--- Table } 4 \text { about here --- }]
\end{aligned}
$$


To contrast understanding the hazard of new sentences, we also ran a competing risks model where technical violations are the primary risk of interest; Table 4 presents the results from this model. Technical violations are of particular concern to PSN; while the project's goal is to lower new gun crimes, PSN hopes to keep returning prisoners from re-arrest or incarceration through exposure to resources often needed to meet their parole conditions. Interestingly, in the technical violations models, some differences emerge amongst the controls which are significant. Here, Blacks are no more like to recidivate from a technical violation than non-Blacks. Additionally, individuals with children have only 95 percent of the hazard of technical violation recidivism (approximately, across the two models) as those without children. Like we saw in the new sentence competing risk models, the PSN experimental group has a significantly lower hazard of technical violations than their counterparts; indeed, they have only 30 percent of the hazard for technical violations than those in the control group. This finding is consistent across both the within and between neighborhood models.

In sum, all models presented here show that the PSN experimental group, in general, is less likely to fail. Additionally their hazard for failing from a new sentence is only 60 percent that of the control group. For technical violations, the difference is even more drastic: they have only 30 percent of the hazard of failing from a technical violation when controlling for the possibility of new sentences. Specifically, the individuals in the PSN experiment are not only less likely to return to prison due to a new sentence, but also much less likely to return to prison because of a technical violation. For the first cohort of the PSN treatment group, in essence, the PSN message is working to reduce new crimes and technical violations among these individuals.

Recidivism by Type of Crime: Competing Risks Hazard Models 
Ultimately, PSN is aimed at reducing gun violence — a message central to the Forums. As such, just as it is essential to know the hazard of new sentences versus technical violations for the treatment and control groups, we also look at the hazard of recidivism to of certain categories of UCR crimes. In Table 5, we display the abbreviated results from these models. Like before, we focus on the within-neighborhood and between-neighborhood distinctions. The controls are suppressed in Table 5; the only coefficient displayed is the PSN Treatment variable ${ }^{8}$.

$$
\text { [--- Table } 5 \text { about here ---] }
$$

Of the nine UCR crimes that were tested, the PSN treatment group had significantly reduced hazards for recidivating from four of the UCR crimes. Like the previous models, we differentiate between within neighborhood models (experimental neighborhood only models) and between neighborhood models (experimental v. control neighborhood models). First, we find that the sub hazard for drug possession versus any other crime for the PSN group, whether in the within or between neighborhood model, is significantly lower than the sub hazard for the control group. The sub hazard for the experimental group is about 63 percent of the sub hazard for the control group; this is across both within and between neighborhood models.

Most relevant for our analysis, however, is the effect of PSN treatment on the hazard of committing a weapons crime, a murder, or a violent crime versus any other crime. Overall, the findings here are reflective of the PSN message being offered to returning offenders in the program. First, the sub hazard of murder (i.e., the hazard of committing murder versus any other crime) for the PSN group, whether in the within or between neighborhood model, is significantly lower than the sub hazard for the control group, so small that the sub hazard is only $3 / 10,000^{\text {th }}$ of a percent in the between neighborhood model and $1 / 100,000^{\text {th }}$ of a percent in the within neighborhood model. In the between neighborhood model that accounts for all neighborhoods in 
the study, the PSN treatment group also has a reduced sub hazard for committing a violent crime over any other crime. Here, the sub hazard for the experimental group is 51.4 percent of the sub hazard of the control group. The sub hazard for committing a weapons crime over any other crime is also lower for the treatment group: 10 percent of the sub hazard for committing a weapons crime than any other crime. In conclusion, we see that with these competing risk models for crime type that the hazard of recidivating through any of the crimes particularly targeted in the PSN treatment is much lower for the experimental group than for the control group. Thus, the PSN message is effectively lowering the incidence of these types of crimes among the target population.

\section{DiscuSsion AND CONCLUSION}

Legitimacy based violence prevention and crime reduction programs like PSN's Offender Notification Forums are guided by a central principle: strengthening perceptions of legitimacy and the perceived fairness of the law leads to higher compliance with the law, even among highly-criminal populations. To date, such legitimacy driven programs have shown to reduce aggregate levels of crime (Braga, Hureau and Papachristos forthcoming; Braga et al. 2001; Carsaro et al. 2012; Engel, Tillyer and Corsaro forthcoming; Papachristos, Meares and Fagan 2007b), yet no study has investigated the role that legitimacy plays in changing individuals' behavior. This study does just that, finding notable reductions in recidivism among a population of parolees returning to Chicago neighborhoods. Our findings are threefold and described below.

First, our results show that attendance at a PSN Forum effectively lengthens participants' time on the street—i.e., people who attend a forum, on average, stay out of prison for longer periods of time. When comparing individuals within the same neighborhood, individuals who 
attended a PSN Forum have a $41 \%$ chance of recidivating before offenders in the control group do; effectively, they are more likely to remain on the street than the control group. Thus, holding constant the neighborhood conditions, PSN participation considerably lowers the likelihood of recidivating. We find this effect across all PSN neighborhoods. This finding suggests that the legitimacy-based message has an effect on individual behavior within neighborhoods that tend to have high-levels of legal cynicism (Kirk and Papachristos 2011).

Secondly, we find that the PSN effect holds for both new offenses net of technical violations; put another way, PSN reduces the likelihood of both a new offense and a technical violation occurring for offenders that attended a PSN forum. In brief, individuals who attended PSN Forum face a hazard of committing a new offense that is 30 percent less than those individuals who did not attend a forum. Keep in mind that using competing risk hazard models, we control for the possibility of technical violations as well as other individual characteristics. This finding is telling: attending a PSN reduces the hazard of being arrested for a new criminal offense, thus facilitating some types of criminal desistance.

Lastly, and perhaps most importantly, we find that the PSN attendees have lower hazards of committing certain serious crimes, such as a weapons crime or a murder. For instance, the subhazard for committing a weapons crime over any other crime is lower for the PSN group: 10 percent of the subhazard for committing a weapons crime than any other crime. The competing risk models for crime type show that for those in the PSN experimental group their hazards of committing certain crimes (i.e., murder, drug possession, and weapons crimes) are lower than the control group. For instance, the PSN treatment group has a 9\% (1/10) chance of committing a weapon crime or a less than $1 \%(1 / 100)$ chance of committing murder before the control group. 
Consequently, PSN is shown to be rather powerful in reducing the likelihood of committing new offenses.

The study has a few limitations that should be noted. First, while the benefit of our sample is that it consists of serious, active offenders, it is also a downfall: we do not know how the Forums might influence less serious offenders. Relatedly, our sample size is smaller as a consequence of the population; with the universe of offenders, the effects may change. Second, it is also possible that altering perceptions of legitimacy and procedural justice have differing effects on juveniles given that their peer groups are more important during this stage of adult development, especially where deviance is concerned (Haynie and Kreager Forthcoming; Warr 2002). Finally, the study takes place in Chicago. Chicago is unique in that is has areas of durable inequality and crime. A program such as PSN may have different effects in other cities. Future research on legitimacy and procedural justice would be benefited by examining individuals in other cities, such as juveniles or those who are less serious offenders.

Limitations notwithstanding, this study has weighty implications for legitimacy-based and focused deterrence strategies. Programs like the Offender Notification Forums appear to exert significant effects on individual behaviors when directed towards those most likely to be engaged in street violence. Put another way, when individual offenders are engaged in fair and just manner, our results suggest that they modify their behavior (stay out of prison longer by reoffender at lower rates). In a sense, this finding provides a partial answer to the question posed by Papachristos, Meares, and Fagan (2012): "Why do criminals obey the law?" Although further research is clearly needed, our results suggest that offenders—-just like the general citizenry—are more likely to comply with the law when they are treating fairly and perceive the agents of the law as acting fairly. More than that, our findings suggest that negative perceptions of the law 
might be altered based on positive interactions and initiatives. And, programs like Chicago's PSN Offender Notification Forums might offer one such option. 
Table 1: Summary Statistics

\begin{tabular}{|c|c|c|c|c|}
\hline & Mean or $\%$ & $\mathrm{SE}$ & Minimum & Maximum \\
\hline Time on the Street (in months) & 18.38 & 0.36 & 0 & 70 \\
\hline Black & $96.05 \%$ & - & 0 & 1 \\
\hline Age in Years & 35.31 & 0.18 & 18 & 77 \\
\hline High School Graduate & $50.86 \%$ & - & - & - \\
\hline Number of Children & 1.94 & 0.03 & 0 & 5 \\
\hline Married & $13.02 \%$ & - & - & - \\
\hline Cohabitating & $1.27 \%$ & - & - & - \\
\hline Prior Incarcerations & 2.23 & 0.02 & 0 & 3 \\
\hline Current Gang Affiliation & $60.39 \%$ & - & - & - \\
\hline First Cohort & $8.67 \%$ & - & - & - \\
\hline Second Cohort & $8.35 \%$ & - & - & - \\
\hline Experimental Neighborhood & $99.68 \%$ & - & - & - \\
\hline Total Recidivism & $72.14 \%$ & - & - & - \\
\hline No Recidivism & $31.22 \%$ & - & - & - \\
\hline New Offense Recidivism & $31.96 \%$ & - & - & - \\
\hline Technical Violation Recidivism & $36.82 \%$ & - & - & - \\
\hline New Offense: Murder & $1.11 \%$ & - & - & - \\
\hline New Offense: Violent & $6.81 \%$ & - & - & - \\
\hline New Offense: Violent Property & $8.22 \%$ & - & - & - \\
\hline New Offense: Drug Sales & $8.00 \%$ & - & - & - \\
\hline New Offense: Drug Possession & $38.75 \%$ & - & - & - \\
\hline New Offense: Weapons & $9.78 \%$ & - & - & - \\
\hline New Offense: Other Property & $1.30 \%$ & - & - & - \\
\hline New Offense: Drug Conspiracy & $0.39 \%$ & - & - & - \\
\hline New Offense: Other & $5.67 \%$ & - & - & - \\
\hline
\end{tabular}
$\mathrm{N}=4220$ 
Table 2: Cox Hazard Models Modeling Time on the Street and Overall Recidivism

\begin{tabular}{|c|c|c|c|c|}
\hline & \multicolumn{2}{|c|}{$\begin{array}{c}\text { Within Neighborhood } \\
\text { Model }\end{array}$} & \multicolumn{2}{|c|}{$\begin{array}{c}\text { Between Neighborhood } \\
\text { Model }\end{array}$} \\
\hline Black & $\begin{array}{l}0.457^{* * * *} \\
(0.116)\end{array}$ & $\begin{array}{l}1.580^{* * *} \\
(0.183)\end{array}$ & $\begin{array}{l}0.247 * * * \\
(0.0930)\end{array}$ & $\begin{array}{l}1.281^{* * *} \\
(0.119)\end{array}$ \\
\hline Age & $\begin{array}{l}0.00529 * \\
(0.00314)\end{array}$ & $\begin{array}{l}1.005^{*} \\
(0.00316)\end{array}$ & $\begin{array}{l}0.00432 * \\
(0.00245)\end{array}$ & $\begin{array}{l}1.004^{*} \\
(0.00246)\end{array}$ \\
\hline High School Educated & $\begin{array}{l}-0.588^{* * *} \\
(0.0519)\end{array}$ & $\begin{array}{l}0.556^{* * * *} \\
(0.0289)\end{array}$ & $\begin{array}{l}-0.569 * * * \\
(0.0403)\end{array}$ & $\begin{array}{l}0.566^{* * * *} \\
(0.0228)\end{array}$ \\
\hline Children & $\begin{array}{l}-0.0665^{* * *} \\
(0.0150)\end{array}$ & $\begin{array}{l}0.936^{* * * *} \\
(0.0141)\end{array}$ & $\begin{array}{l}-0.0555^{* * *} \\
(0.0116)\end{array}$ & $\begin{array}{l}0.946 * * * \\
(0.0110)\end{array}$ \\
\hline Married & $\begin{array}{l}-0.0766 \\
(0.0661)\end{array}$ & $\begin{array}{l}0.926 \\
(0.0612)\end{array}$ & $\begin{array}{l}-0.120^{* *} \\
(0.0513)\end{array}$ & $\begin{array}{l}0.887 * * \\
(0.0455)\end{array}$ \\
\hline Cohabiting & $\begin{array}{l}0.295^{*} \\
(0.155)\end{array}$ & $\begin{array}{l}1.343^{*} \\
(0.208)\end{array}$ & $\begin{array}{l}-0.0231 \\
(0.143)\end{array}$ & $\begin{array}{l}0.977 \\
(0.140)\end{array}$ \\
\hline Gang Member & $\begin{array}{l}0.0174 \\
(0.0284)\end{array}$ & $\begin{array}{l}1.018 \\
(0.0289)\end{array}$ & $\begin{array}{l}0.00608 \\
(0.0216)\end{array}$ & $\begin{array}{l}1.006 \\
(0.0218)\end{array}$ \\
\hline Number of IL Incarcerations & $\begin{array}{l}1.288^{* * *} \\
(0.0694)\end{array}$ & $\begin{array}{l}3.624 * * * \\
(0.251)\end{array}$ & $\begin{array}{l}1.301 * * * \\
(0.0513)\end{array}$ & $\begin{array}{l}3.674 * * * \\
(0.188)\end{array}$ \\
\hline PSN Experimental Group & $\begin{array}{l}-0.841 * * * \\
(0.0995)\end{array}$ & $\begin{array}{l}0.431 * * * \\
(0.0429)\end{array}$ & $\begin{array}{l}-0.852 * * * \\
(0.0983)\end{array}$ & $\begin{array}{l}0.427 * * * \\
(0.0419)\end{array}$ \\
\hline PSN Experimental & & & & \\
\hline Neighborhood & $\begin{array}{l}- \\
-\end{array}$ & $\begin{array}{l}- \\
-\end{array}$ & $\begin{array}{l}-0.0290 \\
(0.0379)\end{array}$ & $\begin{array}{l}0.971 \\
(0.0368)\end{array}$ \\
\hline Observations & 2564 & 2564 & 4220 & 4220 \\
\hline Log Lik & -12924 & -12924 & -22508 & -22508 \\
\hline Chi & 958.8 & 958.8 & 1585 & 1585 \\
\hline
\end{tabular}

Robust standard errors in parentheses

*** $\mathrm{p}<0.01,{ }^{* *} \mathrm{p}<0.05,{ }^{*} \mathrm{p}<0.10$ 
Table 3: Competing Risk Models with New Sentences as the Primary Risk of Interest

\begin{tabular}{|c|c|c|c|c|}
\hline & \multicolumn{2}{|c|}{$\begin{array}{c}\text { Within Neighborhood } \\
\text { Model }\end{array}$} & \multicolumn{2}{|c|}{$\begin{array}{c}\text { Between Neighborhood } \\
\text { Model }\end{array}$} \\
\hline \multirow[t]{2}{*}{ Black } & 0.328 & 1.388 & $0.346^{*}$ & $1.413 *$ \\
\hline & $(0.229)$ & $(0.318)$ & $(0.179)$ & $(0.254)$ \\
\hline \multirow[t]{2}{*}{ Age } & $-0.0110 *$ & $0.989 *$ & $-0.0180 * * *$ & $0.982 * * *$ \\
\hline & $(0.00571)$ & $(0.00565)$ & $(0.00444)$ & $(0.00436)$ \\
\hline \multirow[t]{2}{*}{ High School Educated } & $-0.305 * * *$ & $0.737 * * *$ & $-0.358 * * *$ & $0.699 * * *$ \\
\hline & $(0.0869)$ & $(0.0641)$ & $(0.0695)$ & $(0.0486)$ \\
\hline \multirow[t]{2}{*}{ Children } & -0.0196 & 0.981 & -0.0122 & 0.988 \\
\hline & $(0.0238)$ & $(0.0233)$ & $(0.0190)$ & $(0.0188)$ \\
\hline \multirow[t]{2}{*}{ Married } & -0.0745 & 0.928 & -0.0486 & 0.953 \\
\hline & $(0.110)$ & $(0.102)$ & $(0.0857)$ & $(0.0816)$ \\
\hline \multirow[t]{2}{*}{ Cohabiting } & 0.141 & 1.151 & 0.256 & 1.291 \\
\hline & $(0.295)$ & $(0.340)$ & $(0.239)$ & $(0.309)$ \\
\hline \multirow[t]{2}{*}{ Gang Member } & $0.504 * * *$ & $1.656 * * *$ & $0.557 * * *$ & $1.745 * * *$ \\
\hline & $(0.0498)$ & $(0.0824)$ & $(0.0381)$ & $(0.0665)$ \\
\hline \multirow[t]{2}{*}{ Number of IL Incarcerations } & $0.790 * * *$ & $2.203 * * *$ & $0.676 * * *$ & $1.966 * * *$ \\
\hline & $(0.112)$ & $(0.248)$ & $(0.0830)$ & $(0.163)$ \\
\hline \multirow[t]{2}{*}{ PSN Experimental Group } & $-0.359 * *$ & $0.699 * *$ & $-0.359 * *$ & $0.698 * *$ \\
\hline & $(0.181)$ & $(0.127)$ & $(0.181)$ & $(0.126)$ \\
\hline \multicolumn{5}{|l|}{ PSN Experimental } \\
\hline \multirow[t]{2}{*}{ Neighborhood } & - & - & 0.0353 & 1.036 \\
\hline & - & - & $(0.0618)$ & $(0.0640)$ \\
\hline Observations & 2564 & 2564 & 4220 & 4220 \\
\hline Log Lik & -5477 & -5477 & -8994 & -8994 \\
\hline Chi & 317.2 & 317.2 & 538.4 & 538.4 \\
\hline
\end{tabular}

Robust standard errors in parentheses

$* * * \mathrm{p}<0.01, * * \mathrm{p}<0.05, * \mathrm{p}<0.10$ 
Table 4: Competing Risk Models with Technical Violations as the Primary Risk of Interest Within Neighborhood Model

Between Neighborhood

Model

\begin{tabular}{|c|c|c|c|c|}
\hline & Coefficients & $\begin{array}{c}\text { Hazard } \\
\text { Ratios }\end{array}$ & Coefficients & $\begin{array}{c}\text { Hazard } \\
\text { Ratios }\end{array}$ \\
\hline \multirow[t]{2}{*}{ Black } & 0.327 & 1.386 & 0.0845 & 1.088 \\
\hline & $(0.202)$ & $(0.281)$ & $(0.134)$ & $(0.146)$ \\
\hline \multirow[t]{2}{*}{ Age } & $0.00934 * *$ & $1.009 * *$ & $0.0131 * * *$ & $1.013 * * *$ \\
\hline & $(0.00474)$ & $(0.00478)$ & $(0.00350)$ & $(0.00355)$ \\
\hline \multirow[t]{2}{*}{ High School Educated } & $-0.431 * * *$ & $0.650 * * *$ & $-0.436 * * *$ & $0.647 * * *$ \\
\hline & $(0.0875)$ & $(0.0568)$ & $(0.0668)$ & $(0.0432)$ \\
\hline \multirow[t]{2}{*}{ Children } & $-0.0576^{* *}$ & $0.944 * *$ & $-0.0514 * * *$ & $0.950 * * *$ \\
\hline & $(0.0232)$ & $(0.0219)$ & $(0.0177)$ & $(0.0168)$ \\
\hline \multirow[t]{2}{*}{ Married } & 0.0508 & 1.052 & -0.0376 & 0.963 \\
\hline & $(0.109)$ & $(0.114)$ & $(0.0803)$ & $(0.0773)$ \\
\hline \multirow[t]{2}{*}{ Cohabiting } & 0.117 & 1.125 & -0.283 & 0.753 \\
\hline & $(0.286)$ & $(0.322)$ & $(0.270)$ & $(0.204)$ \\
\hline \multirow[t]{2}{*}{ Gang Member } & $-0.307 * * *$ & $0.735 * * *$ & $-0.327 * * *$ & $0.721 * * *$ \\
\hline & $(0.0376)$ & $(0.0277)$ & $(0.0278)$ & $(0.0200)$ \\
\hline \multirow[t]{2}{*}{ Number of IL Incarcerations } & $0.996 * * *$ & $2.706 * * *$ & $1.067 * * *$ & $2.905 * * *$ \\
\hline & $(0.105)$ & $(0.284)$ & $(0.0789)$ & $(0.229)$ \\
\hline \multirow[t]{2}{*}{ PSN Experimental Group } & $-1.184 * * *$ & $0.306^{* * *}$ & $-1.206^{* * *}$ & $0.299 * * *$ \\
\hline & $(0.202)$ & $(0.0617)$ & $(0.200)$ & $(0.0599)$ \\
\hline \multicolumn{5}{|l|}{ PSN Experimental } \\
\hline \multirow[t]{2}{*}{ Neighborhood } & - & - & -0.0484 & 0.953 \\
\hline & - & - & $(0.0548)$ & $(0.0522)$ \\
\hline Observations & 2564 & 2564 & 4220 & 4220 \\
\hline Log Lik & -6160 & -6160 & -11190 & -11190 \\
\hline Chi & 314.0 & 314.0 & 571.4 & 571.4 \\
\hline
\end{tabular}

Robust standard errors in parentheses

$* * * \mathrm{p}<0.01, * * \mathrm{p}<0.05, * \mathrm{p}<0.10$ 
Table 5: Cox results for separate crimes (coefficients)

\begin{tabular}{|c|c|c|}
\hline & $\begin{array}{l}\text { Within } \\
\text { Neighborhood } \\
\text { Comparison }\end{array}$ & $\begin{array}{l}\text { Between } \\
\text { Neighborhood } \\
\text { Comparison }\end{array}$ \\
\hline \multirow[t]{2}{*}{ Murder } & $-18.22 * * *$ & $-14.93 * * *$ \\
\hline & $(0.408)$ & $(0.293)$ \\
\hline \multirow[t]{2}{*}{ Violent Crime } & -0.660 & $-0.666^{* *}$ \\
\hline & $(0.403)$ & $(0.403)$ \\
\hline \multirow[t]{2}{*}{ Violent Property Crime } & -0.505 & -0.453 \\
\hline & $(0.391)$ & $(0.390)$ \\
\hline \multirow[t]{2}{*}{ Drug Sales } & -0.205 & -0.187 \\
\hline & $(0.324)$ & $(0.321)$ \\
\hline \multirow[t]{2}{*}{ Drug Possession } & $-0.455 * * *$ & $-0.474 * *$ \\
\hline & $(0.137)$ & $(0.137)$ \\
\hline \multirow[t]{2}{*}{ Weapons } & $-2.216 * * *$ & $-2.281 * * *$ \\
\hline & $(0.709)$ & $(0.707)$ \\
\hline \multirow[t]{2}{*}{ Other Property Crime } & 0.584 & 0.683 \\
\hline & $(0.609)$ & $(0.597)$ \\
\hline \multirow[t]{2}{*}{ Drug Conspiracy } & 0.738 & 0.812 \\
\hline & $(0.854)$ & $(0.818)$ \\
\hline \multirow[t]{2}{*}{ Other Crime } & 0.301 & 0.322 \\
\hline & $(0.340)$ & $(0.331)$ \\
\hline $\mathrm{N}$ & 2,564 & 4,220 \\
\hline
\end{tabular}


Figure 1: A Comparison of the Hazard Curves for the Two Treatment and Control groups

\section{Hazard Curves for the Two Treatment and Control Groups}

Cox proportional hazards regression Cox proportional hazards regression
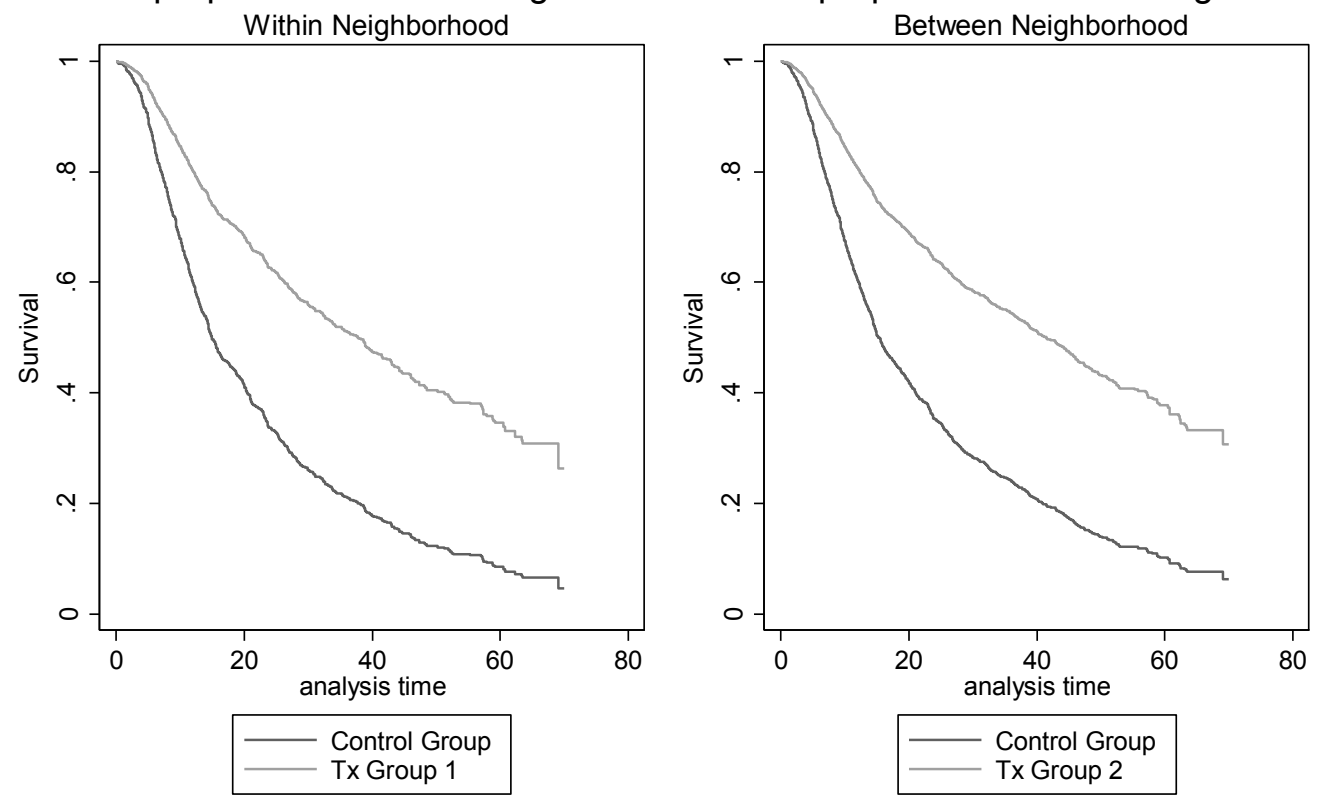

Page 33 of 39 
Figure 2: Comparison of Time on the Street by New Sentences and Technical Violation Failures
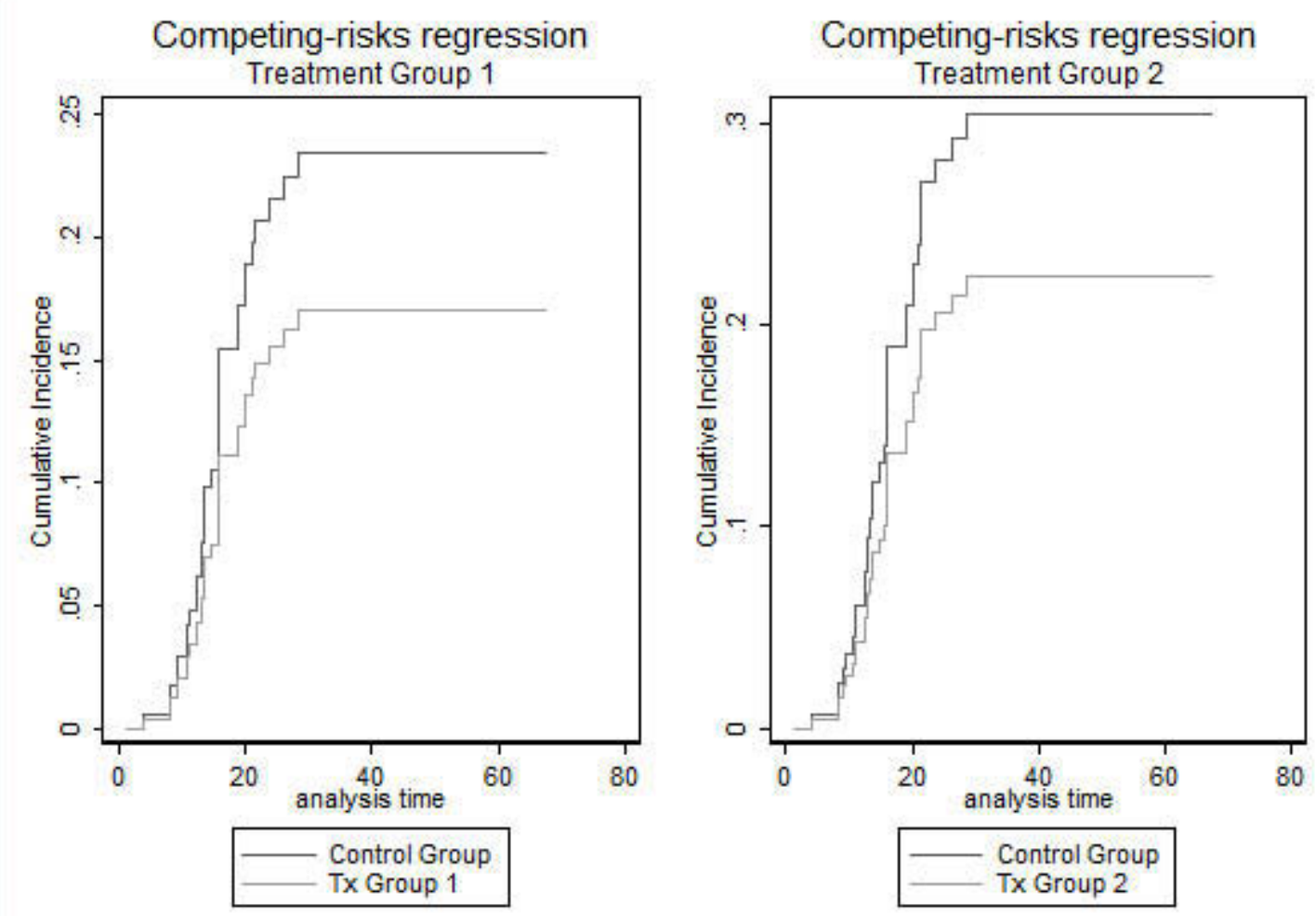


\section{NOTES:}

Allison, Paul D. 1984. Event history analysis: Regression for longitudinal event data: Sage Publications, Incorporated.

Allison, Paul D. 1995. Survival analysis using SAS: A practical guide: Sas Inst.

Braga, A. A., A. M. Piehl, and D. Hureau. 2009. "Controlling Violent Offenders Released to the Community: An Evaluation of the Boston Reentry Initiative." Journal of Research in Crime and Delinquency 46(4):411-36.

Braga, Anthony A. 2003. "Serious Youth Gun Offenders and the Epidemic of Youth Violence in Boston." Journal of Quantitative Criminology 19:33-54.

Braga, Anthony A, David Hureau, and Andrew V. Papachristos. forthcoming. "Deterring GangInvolved Gun Violence: Measuring the Impact of Boston's Operation Ceasefire on Street Gang Behavior " Journal of Quantitative Criminology.

Braga, Anthony A, and David L Weisburd. 2012. "The Effects of Focused Deterrence Strategies on Crime A Systematic Review and Meta-Analysis of the Empirical Evidence." Journal of Research in Crime and Delinquency 49(3):323-58.

Braga, Anthony A., David M. Kennedy, Elin J. Waring, and Anne Morrison Piehl. 2001. "Problem-Oriented Policing, Deterrence, and Youth Violence: An Evaluation of Boston's Operation Ceasefire." Journal of Research in Crime and Delinquency 38(3):195-225.

Carr, Patrick J., Laura Napolitano, and Jessica Keating. 2007. "We Never Call the Cops and Here Is Why: a Qualitative Examination of Legal Cynicism in Three Philadelphia Neighborhoods." Criminology 45:445-80.

Carsaro, Nicholas, Eleazer D. Hunt, Natalie Droovand Hipple, and Edmund F. McGarrell. 2012. "The Impact of Drug Market Pulling Levers Policing on Neighborhood Violence: An Evaluation of the High Point Drug market Intervention." Criminology and Public Policy 11(2):167-99.

Corsaro, Nicholas, Rod K Brunson, and Edmund F McGarrell. 2009. "Problem-oriented policing and open-air drug markets: Examining the Rockford pulling levers deterrence strategy." Crime \& Delinquency.

Corsaro, Nicholas, Eleazer D. Hunt, Natalie Droovand Hipple, and Edmund F. McGarrell. 2012. "The Impact of Drug Market Pulling Levers Policing on Neighborhood Violence: An Evaluation of the High Point Drug market Intervention." Criminology and Public Policy 11(2):167-99.

Engel, Robin S., Marie Skubak Tillyer, and Nicholas Corsaro. forthcoming. "Reducing Gang Violence Using Focused Deterrence: Evaluation the Cincinnati Initiative to Reduce Violence (CIRV)." Justice Quarterly.

Fagan, Jeffrey A., Amanda Geller, Garth Davies, and Valerie West. 2009. "Street Stops and Broken Windows Revisited: The Demography and Logic of Proactive Policing in a Safe and Changing City." Pp. 309-48 in Race, Ethnicity, and Policing: New and Essential Readings, edited by S.K. Rice and M.D. White. New York: New York University Press.

Fagan, Jeffrey, and Alex R Piquero. 2007. "Rational choice and developmental influences on recidivism among adolescent felony offenders." Journal of Empirical Legal Studies 4(4):715-48.

Fine, Jason P., and Robert J. Gray. 1999. "A Proportional Hazards Model for the Subdistribution of a Competing Risk." Journal of the American Statistical Association 94(446):496-509. 
Hagan, John, Carla Shedd, and Monique R. Payne. 2005. "Race, Ethnicy, and Youth Perceptions of Criminal Injustice." American Sociological Review 70(3):81-407.

Haynie, Dana L., and Derek A. Kreager. Forthcoming. "Peer Networks and Crime." in The Oxford Handbook of Criminolgical Theory, edited by Pamela Wilcox and Francis Cullen.

Kennedy, David M. 1996. "Pulling levers: Chronic offenders, high-crime settings, and a theory of prevention." Val. UL Rev. 31:449.

Kennedy, David M, and Sue-Lin Wond. 2009. The high point drug market intervention strategy: US Department of Justice, Office of Community Oriented Policing Services.

Kirk, David S., and Mauri Matsuda. 2011. "Legal Cynicism, Collective Efficacy, and the Ecology of Arrest*." Criminology 49(2):443-72.

Kirk, David S., and Andrew V. Papachristos. 2011. "Cultural Mechanisms and the Persistence of Neighborhood Violence." The American Journal of Sociology 116(4):1190-233.

Lee, Elisa T, and John Wang. 2003. Statistical methods for survival data analysis: WileyInterscience.

Loeber, Ralph, and David P. Farrington. 2011. Young Homicide Offenders and Victims: Risk Factors, Prediction, and Prevention from Childhood. New York: Springer.

Loughran, Thomas A, Alex R Piquero, Jeffrey Fagan, and Edward P Mulvey. 2012. "Differential Deterrence Studying Heterogeneity and Changes in Perceptual Deterrence Among Serious Youthful Offenders." Crime \& Delinquency 58(1):3-27.

McGarrell, Edmund F, Nicholas Corsaro, Natalie Kroovand Hipple, and Timothy S Bynum. 2010. "Project Safe Neighborhoods and violent crime trends in US Cities: assessing violent crime impact." Journal of Quantitative Criminology 26(2):165-90.

Pager, Devah. 2003. "The Mark of a Criminal." American Journal of Sociology 108:937-75.

Papachristos, Andrew V., Anthony A Braga, and David Hureau. 2012. "Social Networks and the Risk of Gunshot Injury." Journal of Urban Health 89(6):992-1003.

Papachristos, Andrew V., Tracey L. Meares, and Jeffery Fagan. 2007a. "Attention Felons: Evaluating Project Safe Neighborhoods in Chicago." Journal of Empirical Legal Studies 4(2):223-72.

Papachristos, Andrew V., Tracey L. Meares, and Jeffrey Fagan. 2007b. "Attention Felons: Evaluating Project Safe Neighborhoods in Chicago." Journal of Empirical Legal Studies 4(2).

Papachristos, Andrew V., Tracey L. Meares, and Jeffrey Fagan. 2012. "Why Do Criminals Obey the Law? The Influence of Legitimacy and Social Networks on Active Gun Offenders." The Journal of Criminal Law \& Criminology 102(2):397-439.

Paternoster, Raymond, Robert Brame, Ronet Bachman, and Lawrence Sherman. 1997. "Do Fair Procedures Matter? The Effect of Procedural Justice on Spouse Assault." Law and Society review 31:163-204.

Reisig, M.D., S.E. Wolfe, and K. Holtfreter. 2011. "Legal Cynicism, Legitimacy, and Criminal Offending The Nonconfounding Effect of Low Self-Control." Criminal Justice and Behavior 38(12):1265-79.

Schnittker, Jason, and Andrea John. 2007. "Enduring Stigma: The Long-Term Effects of Incarceration on Health." Journal of Health and Social Behavior 48:115-30.

Sherman, Lawrence W. 1993. "Defiance, deterrence, and irrelevance: A theory of the criminal sanction." Journal of Research in Crime and Delinquency 30:445-73. 
Skogan, W.G. 2006. "The promise of community policing." Pp. 27-43 in Policing Innovation: Contrasting Perspectives, edited by David Weisburd and Anthony A. Braga. Cambridge: Cambridge University Press.

Tyler, Tom , and Jeffrey Fagan. 2008. "Legitimacy and Cooperation: Why Do People Help the Police Fight Crime in their Communities?" Ohio State Journal of Criminal Law 6(231275).

Tyler, Tom, and Yuen J Huo. 2002. Trust in the Law: Encouraging Public Cooperation with the Police and Courts. New York Russell Sage Foundation.

Tyler, Tom R. 1997. "The psychology of legitimacy: A relational perspective on voluntary deference to authorities." Personality and social psychology review 1(4):323-45.

Tyler, Tom R. 2010. "“Legitimacy in corrections"." Criminology \& Public Policy 9(1):127-34.

Warr, Mark. 2002. Companions in crime: The social aspects of criminal conduct: Cambridge University Press.

Weitzer, Ronald, and Steven A Tuch. 2004. "Race and perceptions of police misconduct." Social Problems 51(3):305-25.

Western, Bruce. 2006. Punishment and Inequality in America. New York: Russell Sage Foundation.

Western, Bruce, and Christopher Wildeman. 2009. "The black family and mass incarceration." The ANNALS of the American Academy of Political and Social Science 621(1):221-42.

Wildeman, C. 2012a. "Imprisonment and Infant Mortality." Social Problems 59(2):228-57.

Wildeman, Christopher. 2012b. "Imprisonment and (Inequality in) Population Health." Social Science Research 41:75-94.

Wolfe, S.E. 2011. "The effect of low self-control on perceived police legitimacy." Journal of Criminal Justice 39(1):67-74.

Wolfgang, Marvin E. 1958. Patterns in Criminal Homicide. Philadelphia, PA: University of Pennsylvania Press.

Wu, Lawrence L, and Nancy Brandon Tuma. 1991. "Assessing bias and fit of global and local hazard models." Sociological Methods \& Research 19(3):354-87.

Yamaguchi, Kazuo. 1991. Event history analysis: Sage Publications, Incorporated. 
${ }^{1}$ The authors would like to thank the members of the Chicago PSN Working Group. This project was supported by Grant \#2006-GP-CX-0017 awarded by the Bureau of Justice Assistance through the Illinois Criminal Justice Information Authority. The Bureau of Justice Assistance is a component of the Office of Justice Programs, which also includes the Bureau of Justice Statistics, the National Institute of Justice, the Office of Juvenile Justice and Delinquency Prevention, and the Office for Victims of Crime. The points of view in this article are those of the authors and in no way express the opinion of the members of the PSN Working Group, the City of Chicago, The State of Illinois, the United States Attorney's Office of the Northern District Illinois, or any of the funding agencies.

${ }^{2}$ The Forums were conducted in several police districts and each district had slight variations in forum structure due to the space available within the district (i.e., the Forum location) but also the varying actors that were involved. Overall, though, the variations across forums are slight. ${ }^{3}$ Indeed, African Americans as a group have higher levels of mistrust in the police, more negative opinions of law enforcement, and tend to live in communities with higher levels of legal cynicism (Kirk and Papachristos 2011; Skogan 2006; Weitzer \& Tuch 2004). The effects of such dramatic racial disparities in incarceration influence other life chances including employment (Western, 2006; Pager, 2003) and individual health and mortality (Schnittker and John, 2007; Wildeman, 2012), and additionally impacts the incarcerated's family members and children (Wildeman, 2010; 2012).

${ }^{4}$ Interestingly, law enforcement partners were initially most skeptical of the Forums, affectionately referring to it as the "hug-a-thug" meeting. 
${ }^{5}$ The PSN team was vigilant of the structure and implementation of the Forums, often conducting "re-boot" sessions when new individuals joined the efforts to ensure the consistency of the message and its delivery.

${ }^{6}$ The following quotes are taken from the ethnographic fieldnotes of the first author whom observed dozens of these meetings during the study period.

${ }^{7}$ All data analysis represents the views of the authors, not the state of Illinois or the Illinois Department of Corrections.

${ }^{8}$ As noted before, the controls in the model include: Black, Age, High School Educated, Children, Married, Cohabiting, Gang Member, Number of Illinois Incarcerations. Additionally, for the within-neighborhood models, we include a control for the PSN experimental group while for the between-neighborhood models, we include both the variables for the PSN experimental group and the PSN neighborhood group. 